\title{
Wilderness Medical Society Practice Guidelines for the Treatment of Acute Pain in Remote Environments
}

\author{
Katie W. Russell, MD; Courtney L. Scaife, MD; David C. Weber, BS; Jeremy S. Windsor, MB ChB; \\ Albert R. Wheeler, MD; William Smith, MD; Ian Wedmore, MD; Scott E. McIntosh, MD, MPH; \\ James R. Lieberman, MD
}

From the Department of Surgery, University of Utah School of Medicine, Salt Lake City, UT (Drs Russell and Scaife); Denali National Park \& Preserve Rescue, Talkeetna, AK (Mr Weber); Chesterfield Royal Hospital, Calow, Derbyshire, United Kingdom (Dr Windsor); St. John's Medical Center, Jackson, WY (Drs Wheeler and Smith); Clinical Faculty, University of Washington School of Medicine, Seattle, WA (Dr Smith); University of Washington School of Medicine, Madigan Army Medical Center, Ft. Lewis, WA (Dr Wedmore); the Division of Emergency Medicine, University of Utah School of Medicine, Salt Lake City, UT (Dr McIntosh); and the Department of Anesthesia, Swedish Medical Center, Seattle, WA (Dr Lieberman).

\begin{abstract}
The Wilderness Medical Society convened an expert panel to develop evidence-based guidelines for the management of pain in austere environments. Recommendations are graded based on the quality of supporting evidence as defined by criteria put forth by the American College of Chest Physicians.
\end{abstract}

Key words: pain control, analgesia, sedation, local anesthesia, wilderness medicine, austere, remote, oligoanesthesia

\section{Introduction}

Evidence suggests that oligoanalgesia, the undertreatment of acute pain, is a recurring issue in the management of patients in the prehospital setting. ${ }^{1,2}$ A recent study evaluating helicopter transfers of 1200 trauma patients found that analgesia was inadequate in $43 \%$ of those transported. ${ }^{2}$ Similar trends are likely to occur in austere environments where medical personnel and supplies are often limited.

Practitioners often report a reluctance to provide adequate pain management because of a wide range of different factors. These include inappropriate estimation of pain by the provider, a lack of medication or the means to administer the necessary analgesics, lack of pharmacologic knowledge, a fear of addiction, concern of masking potential clinical deterioration, and lifethreatening side effects such as respiratory depression, hemodynamic instability, and aspiration. ${ }^{3,4}$

Acute untreated pain is not the only consequence of inadequate analgesia. Failure to adequately manage pain may also cause a significant stress response as well as an increase in the risk of developing posttraumatic stress disorder. ${ }^{5}$ Patients may also become increasingly sensitive to painful stimuli the longer pain remains uncontrolled, making their pain more difficult to control. ${ }^{6}$

Pain management is exceedingly important in the austere environment as practitioners are often faced with

Corresponding author: James Lieberman, MD, University of Washington, School of Medicine, Swedish Medical Center, Department of Anesthesia, 1229 Madison, Suite 1440, Seattle WA 98104 (e-mail: jrlieber@gmail.com). the difficulty of providing prolonged care or dealing with technical extrications. Efficient analgesia reduces both physical and psychological stress and helps to facilitate the comfortable evacuation of these patients to definitive care. $^{7}$

The following are qualities of an ideal pain medication for wilderness use, and should be kept in mind when used in these environments ${ }^{8}$ :

- Compact and lightweight

- Durable

- Nonsedating

- Wide spectrum of use

- Biochemically and environmentally stable

- Multiple routes of administration

- Minimal side effects

The purpose of these guidelines is to provide a literature-based review and simple algorithm for the treatment of acute pain in austere environments. Although an ideal medication does not exist, these guidelines seek to follow such a set of requirements as closely as possible when making recommendations.

Given potential adverse complications of oligoanalgesia, together with the plethora of options now available, we believe that every effort should be made to obtain optimal pain control.

\section{Methods}

A panel convened during the 2013 Annual Winter Meeting of the Wilderness Medical Society in Park City, 
Utah. Invitations were based on the individual's extensive clinical or research experience, and included representatives from emergency medicine, anesthesiology, surgery, military medicine, and the field of prehospital emergency medical services (EMS). Relevant articles were identified through the PUBMED database using a key word search of the following terms: wilderness pain control, prehospital pain, prehospital narcotics, prehospital opioids, prehospital regional anesthesia, fentanyl vs morphine, acetaminophen trauma, ibuprofen trauma, ketamine efficacy, anxiolysis pain, and empathy pain. Searches were initially limited to randomized controlled trials and then expanded to include a broader spectrum of research. This literature review was further supplemented by a hand search of selected articles. The majority of information has been extrapolated from EMS and hospital literature, and very limited evidence is derived directly from the wilderness setting. For the purpose of this paper, the terms remote, austere, tactical, disaster, and wilderness are used interchangeably to describe the varied settings defined by extended patient care times and delayed or difficult access to definitive care. All articles were reviewed and the level of evidence assessed. The panel used a consensus approach to develop recommendations regarding each modality and graded the recommendations according to the criteria developed by the American College of Chest Physicians (Table 1). ${ }^{9}$

\section{Overview of Pain Control}

Indications for pain control in austere environments are typically directed at musculoskeletal injuries including strains, sprains, dislocations, and fractures. Other circumstances that may require similar management include acute medical ailments and environmental injury such as cold injury, bites, stings, and burns. Mechanisms requiring detailed assessment before pain control include traumatic brain injury, spinal cord injury, or airwaycompromised patients. These guidelines do not address specific logistical evacuation issues, but they do aim to make evacuations, when required, more comfortable for patients through improved analgesia. Although narcotics are frequently used for analgesia, the committee recognizes that several other options are available and may be used first and in combination with other medications.

Pain scales are extensively used throughout the medical community. Although visual aids may not be

Table 1. American College of Chest Physicians classification scheme for grading evidence and recommendations in clinical guidelines $^{9}$

\begin{tabular}{|c|c|c|c|}
\hline Grade & Description & Benefits vs risks and burdens & $\begin{array}{l}\text { Methodological quality of } \\
\text { supporting evidence }\end{array}$ \\
\hline $1 \mathrm{~A}$ & $\begin{array}{l}\text { Strong recommendation, } \\
\text { high-quality evidence }\end{array}$ & $\begin{array}{l}\text { Benefits clearly outweigh risks and } \\
\text { burdens or vice versa }\end{array}$ & $\begin{array}{l}\text { RCTs without important limitations } \\
\text { or overwhelming evidence from } \\
\text { observational studies }\end{array}$ \\
\hline $1 \mathrm{~B}$ & $\begin{array}{l}\text { Strong recommendation, } \\
\text { moderate-quality } \\
\text { evidence }\end{array}$ & $\begin{array}{l}\text { Benefits clearly outweigh risks and } \\
\text { burdens or vice versa }\end{array}$ & $\begin{array}{l}\text { RCTs with important limitations or } \\
\text { exceptionally strong evidence } \\
\text { from observational studies }\end{array}$ \\
\hline $1 \mathrm{C}$ & $\begin{array}{l}\text { Strong recommendation, } \\
\text { low-quality or very low } \\
\text { quality evidence }\end{array}$ & $\begin{array}{l}\text { Benefits clearly outweigh risks and } \\
\text { burdens or vice versa }\end{array}$ & Observational studies or case series \\
\hline $2 \mathrm{~A}$ & $\begin{array}{l}\text { Weak recommendation, } \\
\text { high-quality evidence }\end{array}$ & $\begin{array}{l}\text { Benefits closely balanced with risks } \\
\text { and burdens }\end{array}$ & $\begin{array}{l}\text { RCTs without important limitations } \\
\text { or overwhelming evidence from } \\
\text { observational studies }\end{array}$ \\
\hline $2 \mathrm{~B}$ & $\begin{array}{l}\text { Weak recommendation, } \\
\text { moderate-quality } \\
\text { evidence }\end{array}$ & $\begin{array}{l}\text { Benefits closely balanced with risks } \\
\text { and burdens }\end{array}$ & $\begin{array}{l}\text { RCTs with important limitations or } \\
\text { exceptionally strong evidence } \\
\text { from observational studies }\end{array}$ \\
\hline $2 \mathrm{C}$ & $\begin{array}{l}\text { Weak recommendation, } \\
\text { low-quality or very low } \\
\text { quality evidence }\end{array}$ & $\begin{array}{l}\text { Uncertainty in the estimates of } \\
\text { benefits, risks and burden; } \\
\text { benefits, risk and burden may be } \\
\text { closely balanced }\end{array}$ & Observational studies or case series \\
\hline
\end{tabular}

RCT, randomized controlled trial.

Source: Guyatt G, Gutterman D, Baumann MH, et al. Grading strength of recommendations and quality of evidence in clinical guidelines; report from an American College of Chest Physicians task force. Chest. 2006; 129:174-181. 
Table 2. Verbal numeric rating scale for assessment of pain. ${ }^{10}$

\begin{tabular}{ll}
\hline Numeric rating scale & Pain assessment \\
\hline 0 & No pain \\
$1-3$ & Mild pain \\
$4-6$ & Moderate pain \\
$7-10$ & Severe pain \\
\hline
\end{tabular}

available in the backcountry, a numeric rating scale (NRS; Table 2$)^{10}$ can still be used. These help to provide an initial assessment and aid caregivers wishing to quantify any response to treatment.

The Figure outlines the recommended approach to escalating analgesic care for the typical backcountry patient. The authors created this pyramid for wilderness use, based on widely adopted pain algorithms that have previously been shown to be effective. ${ }^{11}$ By beginning care at the base of the pyramid, providers can focus their attention first on using the safest and most accessible interventions before any escalation of care.

As care is escalated up the pyramid, more-invasive modalities are incorporated into the patient's treatment. Potent drugs with potentially harmful side effects will thus be reserved for those in extreme pain, and only after safer, less-invasive therapies have been considered.

It is important that providers practice within their scope of practice or licensure. Scope of practice is a terminology used by national, state, and provincial licensing boards for various professions that seeks to define the procedures and actions that are permitted for the licensed individual. Providers should not administer treatments if they are not qualified by licensure, or through ability. In the United States, protocols exist that

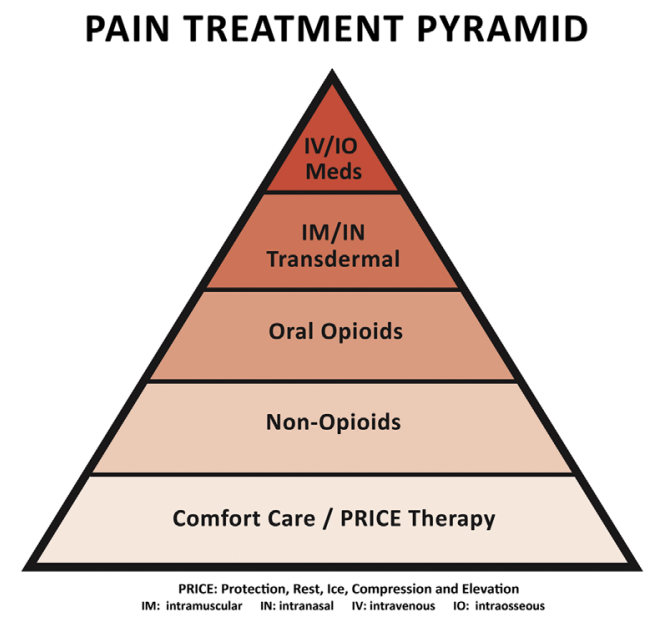

Figure. Pain management pyramid. IM, intramuscular; IN, intranasal; IO, intraosseous; IV, intravenous; PRICE, protection, rest, ice, compression, and elevation. allow some nonphysician prehospital providers to practice above what urban licensure allows. This is termed an "expanded scope of practice." This can allow nonphysician providers, for example, to administer prescription medications when indicated.

Recommendation: Wilderness providers should receive appropriate education and practice in various pain management techniques, commensurate with their scope of practice, in order to provide optimal pain control for patients in wilderness environments. Recommendation grade: $1 \mathrm{C}$.

\section{COMFORT CARE}

Healthcare teams often overlook the utility of comforting those patients with pain and anxiety. Simple techniques, such as regularly using the patient's name and reviewing the plan for pain management with the patient, can be very comforting, thereby decreasing their anxiety and often improving their perception of pain. This is particularly important if pain medications are not available. Sambo et $\mathrm{al}^{12}$ studied visual analog scales and empathy and noted anxious individuals experienced "less pain in the presence of an 'empathetic' other." They also found lower heart rate responses to pain when individuals were not alone. ${ }^{12}$ Designating an individual as the primary caretaker, especially for prolonged extrications, can be helpful in maximizing patient comfort and minimizing miscommunication. Because there are virtually no negative side effects to providing comfort care, this is a valuable technique that should always be included in patient management.

Recommendation: Attention to empathy should be used as first-line treatment of pain in all wilderness patient care. Recommendation grade: 1B.

\section{PRICE TREATMENT PROTOCOL}

Treatment for acute injuries has traditionally involved some variation of the RICE acronym (rest, ice, compression, and elevation). The physiological basis underpinning this approach is to reduce the formation of edema that results from injury. Extensive edema can be both painful and detrimental to the process of tissue healing. ${ }^{13}$ Currently, PRICE (including protection of the injury) is considered the optimal treatment regimen for muscular injury and fracture, ${ }^{13}$ whereas the MEAT (movement, exercise, analgesics, and treatments) protocol has been proposed for managing ligament and tendon injury because some inflammation actually promotes healing in these circumstances. ${ }^{14}$ In a remote setting, it is difficult to differentiate between these injury patterns, and for this reason PRICE is still the recommended therapy for all acute soft tissue injuries. 
If an isolated ligament or tendon injury is highly suspected, MEAT therapy can be considered.

The following treatment strategies are recommended for optimal outcomes when enlisting the PRICE protocol:

1. Protection from further injury and providing stability in the form of taping, bracing, or splinting.

2. Rest can reduce further inflammation and pain. This said, patients can still be encouraged to self-ambulate during evacuation whenever appropriate.

3. Ice, when available, can decrease skin temperature to $15^{\circ} \mathrm{C}$, at which point nerve conduction is inhibited and pain decreases. ${ }^{13}$ It also reduces edema formation. This should be performed at 10-minute intervals, or whenever practical, for the first 24 to 48 hours after injury. ${ }^{14}$ If this is logistically feasible during an evacuation, Algafly et $\mathrm{al}^{15}$ recommend 10 minutes on followed by 10 minutes off, and repeat, taking care to avoid frostbite or hypothermia, especially if the injured area becomes numb. When ice or snow is not available, cold water may be substituted for this therapy.

4. Compression, with an elastic bandage, aims to reduce the swelling secondary to the acute inflammatory process. The bandage should be close fitting without compromising the circulation and should still allow adequate muscle expansion and sufficient blood flow. Bandages should be checked periodically to avoid overcompression.

5. Elevation of the injured area above the level of the heart will increase venous return to the systemic circulation and thus reduce potential swelling and aid the removal of waste products.

Recommendation: The PRICE therapy should be used for acute injury and pain, concurrently with empathy as first-line treatment of pain in all wilderness patient care. Recommendation grade: $1 \mathrm{~B}$.

\section{NONOPIOID ANALGESIA}

Nonopioid medications have fewer side effects than opioids and often prove very effective in the management of acute pain. Therefore, when medications are required for pain control in remote environments, these should be considered first. In multiple prospective, randomized controlled trials, the combination of a nonsteroidal anti-inflammatory (NSAID) medication with acetaminophen has been demonstrated to provide superior pain control to either drug alone or in combination with an oral narcotic. The side effects have been shown to be reduced, and patient satisfaction was reported as being higher. These benefits have been seen across different injury patterns and in postoperative patients. ${ }^{16-18}$ A systematic review of 21 studies over 10 years found that combining acetaminophen and an NSAID was superior to either drug prescribed alone. ${ }^{19}$ Military applications of both NSAIDs and acetaminophen have also been successful. ${ }^{20,21}$ In fact, some US military units give all soldiers a "combat pill pack" to be taken immediately after a penetrating extremity wound of any type. These packs contain acetaminophen, an NSAID, and an antibiotic. ${ }^{8}$ Acute pain can be treated, in part or completely, with appropriately dosed nonnarcotics before opioids are introduced. For severe pain, the initial dose should be simultaneous, after which the medications can be administered in a simultaneous fashion or at staggered intervals.

Ketorolac is another commonly used NSAID that is often given IV or intramuscularly (IM). As an analgesic, its opioid-sparing effects have been demonstrated in numerous studies. ${ }^{22,23}$ It is particularly useful when oral NSAIDs cannot be administered, although studies show no difference in reduction of pain scores when IM ketorolac is compared with oral ibuprofen. ${ }^{24}$ NSAIDs do have adverse effects. They can cause renal injury, especially in dehydrated patients, and inhibit platelet function, which can increase bleeding. An association between gastrointestinal injury and long-term use of NSAIDs is also well known. Little data exist about assessing acute bleeding risk after trauma, but to extrapolate from surgical literature, multiple studies have shown that no increase in postoperative bleeding occurs with short-term use of NSAIDs. ${ }^{25,26}$ Although prolonged use can cause peptic ulcer disease, short-term use for up to 10 days of over-the-counter NSAIDs with standard dosing has been shown to be extremely safe and well tolerated. ${ }^{27-29}$ An ibuprofen dose of $1200 \mathrm{mg} /$ day or less or naproxen at $660 \mathrm{mg} / \mathrm{d}$ or less has no greater risk than placebo. ${ }^{27}$ Giving NSAIDs with food can alleviate gastrointestinal symptoms, and if significant abdominal pain develops, the medication should be stopped.

The most important side effect related to acetaminophen use is the possibility of liver failure related to overdose. Prescription-dose acetaminophen up to $4 \mathrm{~g} / \mathrm{d}$ in an adult is still appropriate for short-term use. It is considered safe in intoxicated patients, but care should be taken in chronic alcoholics and patients with hepatic dysfunction. ${ }^{30,31}$

As the basis of medical therapy for acute injury, these medications should be regularly dosed throughout the acute injury period.

Recommendation: Combining acetaminophen with an NSAID should be used as the first-line medication 
treatment of acute pain in the wilderness, unless there is a specific patient allergy or other contraindication. Recommendation grade: $1 \mathrm{~A}$.

\section{OPIOID ANALGESIA}

If additional medication is required, as indicated by a patient's NRS score, a move to the next level of the pyramid is recommended. When there is concern about the patient's level of consciousness, regular monitoring is required and caution should be applied when providing any analgesic agent that could have a sedative effect. Providing opioid analgesia can be challenging in the backcountry setting and may be associated with a wide range of side effects, including dysphoria, euphoria, pruritus, nausea and vomiting, sedation, loss of airway reflexes, and constipation. Nonetheless, opioids have a clear role in the treatment of moderate-to-severe pain. Universal standards for the type, dose, and mode of administration of opioid in the prehospital environment remain unclear.

Compared with parenteral preparations, oral formulations of opioids have the benefit of being easier to carry, store, and administer. Therefore, these should be the most common opioid preparation carried on wilderness expeditions. Frequently, individuals, other than the providers, will carry their own opioids. Combination drugs such as those containing hydrocodone and acetaminophen (Vicodin) or oxycodone and acetaminophen (Percocet) can also be used provided that the daily maximum recommended dose of acetaminophen is not exceeded.

Medical providers in the United States and certain other countries are typically restricted to prescribing and administering medications only to the specific recipient; third-party prescribing and administering is not legally allowed in most states. A common method to comply with these laws while still carrying pain medications is for each participant to bring a supply of medications prescribed by their personal doctor.

Recommendation: Providers with appropriate licensing should carry at least 1 form of an oral opioid into the wilderness for the treatment of acute moderate and severe pain. Recommendation grade: $2 \mathrm{~B}$.

\section{Transmucosal narcotics}

Oral transmucosal fentanyl citrate (OTFC) is an effective means of delivering noninvasive rapid-onset pain control. Several military studies, including one with 286 patients, have concluded that OTFC provides safe and effective analgesia in the prehospital combat setting. ${ }^{10,32}$ Literature on burn patients also supports its use. ${ }^{33}$ This application of fentanyl has not yet become widespread in the backcountry, but has promising potential as it harbors many of the ideal qualities discussed previously_-good efficacy, rapid onset, noninvasive administration, and relative ease of packing.

Recommendation: Transmucosal opioids should be used as a safe option for acute moderate-to-severe pain in remote environments. Recommendation grade: 1B.

\section{Intranasal narcotics}

Intranasal (IN) administration of narcotics provides an easy to administer, noninvasive, low-cost, rapid-onset route for providing analgesia to the injured patient. Multiple prospective, randomized, controlled trials have shown intranasal fentanyl (INF) to be equivalent in terms of efficacy compared with IV morphine. Advantages are rapid onset of pain relief without the need for IV access. ${ }^{34,35}$ Bioavailability is estimated at $71 \%$ for INF, necessitating a conversion to $1.4 \mathrm{x}$ IV doses. ${ }^{35}$ Sufentanil requires a lower volume because of its higher concentration and has been shown to be safe and effective in reducing pain in a ski clinic. ${ }^{36}$ There are several key concepts to consider when administering IN medications: 1) the drug concentration must be maximized in the smallest volume, 2) the dose must be sufficient to overcome bioavailability limitations of the nasal mucosa, and 3) both nostrils should be used to maximize absorptive surface. ${ }^{37}$ Based on these concepts, the most concentrated narcotic will be the easiest to use. In the United States, sufentanil would be ideal. In some countries fentanyl has been concentrated to $300 \mu \mathrm{g} / \mathrm{mL}$, making adequate nasal dosing easily achievable with minimal volume.

Recommendation: Intranasal opioids should be considered as highly effective safe options for acute moderate-to-severe pain control in the wilderness. Recommendation grade: $1 \mathrm{~B}$.

\section{Intramuscular narcotics}

Intramuscular injection of pain medication has been an important route of administration in many prehospital and hospital environments. Although the onset and efficacy may be inferior to alternative routes ${ }^{38}$ most narcotics can be given IM and it remains an option for patients without vascular access or when other routes of administration are inappropriate or unavailable. Of note, variations in muscle blood flow during hypoperfusion from cold temperatures or shock may make absorption rates less predictable. ${ }^{39}$ Newer administration techniques, such as IN and transmucosal routes, are replacing the reliance on IM injection for delivery of pain medications.

Recommendation: Intramuscular injections of narcotics can be efficacious for acute moderate-to-severe 
pain in the wilderness; however, supporting evidence is lacking. Recommendation grade: $2 \mathrm{~B}$.

\section{Intravenous narcotics}

Intravenous medications provide fast and effective analgesia. However, this may be more difficult in austere environments as IV access requires considerable experience and suitable equipment. Intraosseous access (IO) is a viable alternative, and should be considered when IV access cannot be readily obtained. ${ }^{40}$

Intravenous analgesia has several advantages. It provides rapid pain relief and reliable drug delivery and is a familiar mode of administration for healthcare professionals. In terms of drug choice, fentanyl and morphine have been compared prospectively and proven equivalent in terms of analgesia and side effects. ${ }^{41}$ Fentanyl has been recommended as the drug of choice for prehospital IV pain control. ${ }^{42}$ It has a rapid onset (within 5 minutes) and a hemodynamically stable profile that is advantageous in trauma patients. Although the extra equipment and invasive nature of an IV medication makes it unreasonable for many austere settings, once IV or IO access is established these medications are still considered the gold standard for pain control. The availability of IV medications may be more reasonable in base camp scenarios where prolonged stays and delayed evacuations are more likely to occur.

Recommendation: Either IV or IO opioids, when available, should be used for acute moderate-to-severe pain in the wilderness environment when repeated doses of medications are required and need to be titrated continually. Recommendation grade: $1 \mathrm{~A}$.

\section{Transdermal narcotics}

Transdermal opioids can be effective in treating subacute pain for extended patient care scenarios. Fentanyl is the most common narcotic available for this route. This noninvasive method may provide consistent medication administration, making it ideal when longer-term or subacute pain control is warranted, such as for a long evacuation after stabilization. Its small size and low cost also make it an attractive wilderness analgesic. Disadvantages include its slower onset, erratic absorption, and complications, especially respiratory depression.

Recommendation: The committee has no recommendations regarding transdermal opioids. Although they can be useful in certain stable evacuation situations, there are other excellent alternatives available.

\section{Reversal agents}

Respiratory failure caused by opioid administration should always be a concern, and the ability to treat these side effects should always be available. However, with careful titration of opioid medications, this problem should be avoided.

Recommendation: All providers who administer opioid analgesics should be proficient in managing the patient's airway and respiratory status. Naloxone may be carried as an adjunct. Recommendation grade: $1 \mathrm{C}$.

\section{KETAMINE}

Ketamine is a dissociative anesthetic agent and analgesic that has a number of applications in the wilderness setting. It can be used alone at higher dissociative doses for moderate to deep sedation during painful procedures. In smaller doses it can be used alone to treat pain, or in combination with opioids to enhance pain control. Ketamine is well tolerated, and has been shown to be safe when administered by nonphysician practitioners. ${ }^{43}$ However, caution should be used to stay within a practitioner's scope of practice and experience. In appropriately titrated doses, patients can maintain their own airway because pharyngeal reflexes and spontaneous ventilation are preserved. Patients are usually amnestic after the event, which is beneficial if a prolonged evacuation ensues. Important side effects are related to increasing sympathetic discharge, resulting in increased heart rate and blood pressure, as well as increased salivation. Therefore, in higher doses adequate airway management skills are required. Ketamine is also a suitable choice when cardiovascular compromise is present.

There is growing evidence that ketamine may be safely used with nonperiorbital injuries. Halstead et $\mathrm{al}^{44}$ demonstrated no rise in intraocular pressure with ketamine for procedural sedation in 80 pediatric patients with nonperiorbital injuries. However, further clinical studies are required, and caution is advised with ocular trauma or glaucoma.

Ketamine is particularly useful in procedures that may cause extreme pain but are of short duration, including fracture reduction, manipulation in a confined space, wound repair, and amputations. It has been used successfully for procedures at high altitudes $(4243 \mathrm{~m}) .^{45}$ Additionally, ketamine can be given through many routes: IM, IV, or less commonly IN, oral, sublingual, and rectal.

Recommendation: Ketamine should be used as an advanced-tier method for controlling acute moderate-tosevere pain in the wilderness setting. Recommendation grade: $1 \mathrm{~B}$.

\section{LOCAL AND REGIONAL ANESTHESIA}

Local anesthesia can provide a safe and effective means of analgesia for the injured patient in the wilderness. Nerve blocks can be used for analgesia for fractures, soft tissue trauma (including lacerations and crush injuries), 
Table 3. Recommended drug doses for adult and pediatric patients

\begin{tabular}{|c|c|c|c|c|c|}
\hline Drug & Adult dose & Pediatric dose & Route & Frequency & Maximal dose $/ 24 h$ \\
\hline \multicolumn{6}{|l|}{ Intravenous agents } \\
\hline Fentanyl & $1-2 \mu \mathrm{g} / \mathrm{kg}(50-100 \mu \mathrm{g})$ & $0.5-2 \mu \mathrm{g} / \mathrm{kg}$ & IV & 5-15 minutes & Titrate to effect \\
\hline Ketamine & $\begin{array}{l}0.3-4 \mathrm{mg} / \mathrm{kg}(20 \mathrm{mg} \\
\text { IV for pain) }\end{array}$ & $0.3-4 \mathrm{mg} / \mathrm{kg}$ & IV & 5-15 minutes & Titrate to effect \\
\hline Morphine & $1-5 \mathrm{mg}$ & $0.1 \mathrm{mg} / \mathrm{kg}$ & IV & $15-30$ minutes & Titrate to effect \\
\hline \multicolumn{6}{|l|}{ IM/IN/transdermal agents } \\
\hline Fentanyl & $200-1600 \mu \mathrm{g}$ lozenge & N/A & OTFC & $15-30$ minutes & Titrate to effect \\
\hline Fentanyl & $2 \mu \mathrm{g} / \mathrm{kg}(100 \mu \mathrm{g})$ & $0.5-1.5 \mu \mathrm{g} / \mathrm{kg}$ & IM/IN & $15-30$ minutes & Titrate to effect \\
\hline Ketamine & $\begin{array}{l}0.5-4 \mathrm{mg} / \mathrm{kg}(50- \\
100 \mathrm{mg})\end{array}$ & $0.3-4 \mathrm{mg} / \mathrm{kg}$ & $\mathrm{IM} / \mathrm{IN}$ & 15-30 minutes & Titrate to effect \\
\hline Morphine & $5-10 \mathrm{mg}$ & $0.1 \mathrm{mg} / \mathrm{kg}$ & $\mathrm{IM}$ & 30 minutes & Titrate to effect \\
\hline \multicolumn{6}{|l|}{ Oral opioid agents } \\
\hline Hydromorphone & $2-4 \mathrm{mg}$ & $0.05-0.1 \mathrm{mg} / \mathrm{kg}$ & $\mathrm{PO}$ & 4-6 hours & Titrate to effect \\
\hline Oxycodone & $5-15 \mathrm{mg}$ & $0.1 \mathrm{mg} / \mathrm{kg}$ & $\mathrm{PO}$ & 4-6 hours & \\
\hline \multicolumn{6}{|l|}{ Oral nonopioid } \\
\hline Acetaminophen & $650-1000 \mathrm{mg}$ & $\begin{array}{l}15 \mathrm{mg} / \mathrm{kg} * \text { Do } \\
\text { not exceed } 75 \\
\mathrm{mg} / \mathrm{kg} \text { per day }\end{array}$ & $\mathrm{PO}$ & 6 hours & $4 \mathrm{~g}$ adult \\
\hline $\begin{array}{l}\text { Ibuprofen (substitute } \\
\text { NSAIDs per package } \\
\text { recommendations) }\end{array}$ & $600-800 \mathrm{mg}$ & $\begin{array}{l}10 \mathrm{mg} / \mathrm{kg} \text { per } \\
\text { dose }\end{array}$ & $\mathrm{PO}$ & 6 hours & $2400 \mathrm{mg}$ adult \\
\hline
\end{tabular}

IM, intramuscular; IN, intranasal; NSAID, nonsteroidal anti-inflammatory drug; OTFC, oral transmucosal fentanyl citrate; PO, orally (per os).

and procedures including removal of foreign bodies and suturing. With appropriate training, regional anesthesia may be a feasible option for well-trained and practiced providers. Prehospital femoral nerve blocks for femur fracture have been shown to be a safe and effective method of acute pain control when performed by experienced physicians, typically anesthesiologists. ${ }^{46,47}$ Attention needs to be paid to avoid intravascular injection by aspiration before injection and to stay within recommended dosing to avoid life-threatening toxicity. Regional blocks that can be provided in the wilderness with appropriate expertise include digital block, hematoma block, intercostal block, and distal nerve block. ${ }^{48}$ If a practitioner is prepared to suture wounds, local anesthetic should be strongly considered. Full discussion of the techniques of regional blocks is beyond the scope of this article.

Recommendation: Local anesthetics are a safe and effective option for controlling acute pain in the remote or wilderness setting. Recommendation grade: $1 \mathrm{~B}$.

A summary of these medications is provided in Table 3.

\section{ADJUNCT MEDICATIONS}

Anxiety can play an important role in elevating a patient's pain. It affects not only the patient but also providers. Although benzodiazepines are commonly used as an adjunct to anesthesia and analgesia in the hospital environment, there has been no significant research that evaluates the use of anxiolytics in the prehospital setting. Some physicians promote the use of benzodiazepines for their muscle-relaxant properties, but the choice to carry these must be left to the individual provider. Given the lack of research, the potential for side effects, and the practical considerations of weight and space, the committee makes no formal recommendations for adjunctive anxiolytics at this time.

\section{Conclusions}

This article provides a summary of available evidence for treatment of pain in remote settings. Most evidence is taken from the EMS, hospital, and military literature. Although minimal literature exists directly related to wilderness pain control, many similarities exist with other specialties, and some conclusions can be drawn. A baseline algorithm and additional options for advanced practitioners have been described in these guidelines. The goal is to better prepare providers who venture into the backcountry, and ensure that better treatment is available for those suffering from pain.

\section{References}

1. Middleton PM, Simpson PM, Sinclair G, Dobbins TA, Math B, Bendall JC. Effectiveness of morphine, fentanyl, 
and methoxyflurane in the prehospital setting. Prehosp Emerg Care. 2010;14:439-447.

2. Albrecht E, Taffe P, Yersin B, Schoettker P, Decosterd I, Hugli O. Undertreatment of acute pain (oligoanalgesia) and medical practice variation in prehospital analgesia of adult trauma patients: a $10 \mathrm{yr}$ retrospective study. $\mathrm{Br} \mathrm{J}$ Anaesth. 2013;110:96-106.

3. Rupp T, Delaney KA. Inadequate analgesia in emergency medicine. Ann Emerg Med. 2004;43:494-503.

4. Davidson EM, Ginosar Y, Avidan A. Pain management and regional anaesthesia in the trauma patient. Curr Opin Anaesthesiol. 2005;18:169-174.

5. Holbrook TL, Galarneau MR, Dye JL, Quinn K, Dougherty AL. Morphine use after combat injury in Iraq and posttraumatic stress disorder. N Engl J Med. 2010;362:110-117.

6. Ducharme J. Acute pain and pain control: state of the art. Ann Emerg Med. 2000;35:592-603.

7. Chambers JA, Guly HR. The need for better pre-hospital analgesia. Arch Emerg Med. 1993;10:187-192.

8. Wedmore IS, Johnson T, Czarnik J, Hendrix S. Pain management in the wilderness and operational setting. Emerg Med Clin North Am. 2005;23:585-601.

9. Guyatt G, Gutterman D, Baumann MH, et al. Grading strength of recommendations and quality of evidence in clinical guidelines: report from an American College of Chest Physicians task force. Chest. 2006;129:174-181.

10. Wedmore IS, Kotwal RS, McManus JG, et al. Safety and efficacy of oral transmucosal fentanyl citrate for prehospital pain control on the battlefield. J Trauma Acute Care Surg. 2012;73(6 suppl 5):S490-S495.

11. Zech DF, Grond S, Lynch J, Hertel D, Lehmann KA. Validation of World Health Organization Guidelines for cancer pain relief: a 10-year prospective study. Pain. 1995;63:65-76.

12. Sambo CF, Howard M, Kopelman M, Williams S, Fotopoulou A. Knowing you care: effects of perceived empathy and attachment style on pain perception. Pain. 2010;151:687-693.

13. Bleakley CM, O'Connor S, Tully MA, Rocke LG, MacAuley DC, McDonough SM. The PRICE study (Protection Rest Ice Compression Elevation): design of a randomised controlled trial comparing standard versus cryokinetic ice applications in the management of acute ankle sprain [ISRCTN13903946]. BMC Musculoskelet Disord. 2007;8:125.

14. Bleakley CM, O'Connor SR, Tully MA, et al. Effect of accelerated rehabilitation on function after ankle sprain: randomised controlled trial. BMJ. 2010;340:c1964.

15. Algafly AA, George KP. The effect of cryotherapy on nerve conduction velocity, pain threshold and pain tolerance. Br J Sports Med. 2007;41:365-369.

16. Sniezek PJ, Brodland DG, Zitelli JA. A randomized controlled trial comparing acetaminophen, acetaminophen and ibuprofen, and acetaminophen and codeine for postoperative pain relief after Mohs surgery and cutaneous reconstruction. Dermatol Surg. 2011;37:1007-1013.

17. Mitchell A, van Zanten SV, Inglis K, Porter G. A randomized controlled trial comparing acetaminophen plus ibuprofen versus acetaminophen plus codeine plus caffeine after outpatient general surgery. J Am Coll Surg. 2008;206: 472-479.

18. Clark E, Plint AC, Correll R, Gaboury I, Passi B. A randomized, controlled trial of acetaminophen, ibuprofen, and codeine for acute pain relief in children with musculoskeletal trauma. Pediatrics. 2007;119:460-467.

19. Ong CKS, Seymour RA, Lirk P, Merry AF. Combining paracetamol (acetaminophen) with nonsteroidal antiinflammatory drugs: a qualitative systematic review of analgesic efficacy for acute postoperative pain. Anesth Analg. 2010;110:1170-1179.

20. Black IH, McManus J. Pain management in current combat operations. Prehosp Emerg Care. 2009;13:223-227.

21. Aldington DJ, McQuay HJ, Moore RA. End-to-end military pain management. Philos Trans $R$ Soc Lond $B$ Biol Sci. 2011;366:268-275.

22. Wheatley RG. Analgesic efficacy of ketorolac. Acta Anaesthesiol Belg. 1995;47:135-142.

23. Gillis JC, Brogden RN. Ketorolac. A reappraisal of its pharmacodynamic and pharmacokinetic properties and therapeutic use in pain management. Drugs. 1997;53:139-188.

24. Arora S, Wagner JG, Herbert M. Myth: parenteral ketorolac provides more effective analgesia than oral ibuprofen. CJEM. 2007;9:30-32.

25. Cardwell ME, Siviter G, Smith AF. Nonsteroidal antiinflammatory drugs and perioperative bleeding in paediatric tonsillectomy. Chichester, UK: Wiley. The Cochrane Library Issue 10, 2010.

26. Forrest JB, Heitlinger EL, Revell S. Ketorolac for postoperative pain management in children. Drug Saf. 1997;16:309-329.

27. Ong CKS, Lirk P, Tan CH, Seymour RA. An evidencebased update on nonsteroidal anti-inflammatory drugs. Clin Med Res. 2007;5:19-34.

28. Rampal P, Moore N, Van Ganse E, et al. Gastrointestinal tolerability of ibuprofen compared with paracetamol and aspirin at over-the-counter doses. J Int Med Res. 2002;30:301-308.

29. Le Parc JM, Van Ganse E, Moore N, Wall R, Schneid H, Verrière F. Comparative tolerability of paracetamol, aspirin and ibuprofen for short-term analgesia in patients with musculoskeletal conditions: results in 4291 patients. Clin Rheumatol. 2002;21:28-31.

30. Zimmerman HJ, Maddrey WC. Acetaminophen (paracetamol) hepatotoxicity with regular intake of alcohol: analysis of instances of therapeutic misadventure. Hepatology. 1995;22:767-773.

31. Schmidt LE, Dalhoff K, Poulsen HE. Acute versus chronic alcohol consumption in acetaminophen-induced hepatotoxicity. Hepatology. 2002;35:876-882.

32. Kotwal RS, O'Connor KC, Johnson TR, Mosely DS, Meyer DE, Holcomb JB. A novel pain management strategy for combat casualty care. Ann Emerg Med. 2004;44:121-127.

33. Robert R, Brack A, Blakeney P, et al. A double-blind study of the analgesic efficacy of oral transmucosal fentanyl citrate and oral morphine in pediatric patients 
undergoing burn dressing change and tubbing. J Burn Care Rehabil. 2003;24:351-355.

34. Rickard C, O'Meara P, McGrail M, Garner D, McLean A, Le Lievre PA. randomized controlled trial of intranasal fentanyl vs intravenous morphine for analgesia in the prehospital setting. Am J Emerg Med. 2007;25:911-917.

35. Borland M, Jacobs I, King B, O'Brien D. A randomized controlled trial comparing intranasal fentanyl to intravenous morphine for managing acute pain in children in the emergency department. Ann Emerg Med. 2007;49:335-340.

36. Steenblik J, Goodman M, Davis V, et al. Intranasal sufentanil for the treatment of acute pain in a winter resort clinic. Am J Emerg Med. 2012;30:1817-1821.

37. Wolfe TR, Bernstone T. Intranasal drug delivery: an alternative to intravenous administration in selected emergency cases. J Emerg Nurs. 2004;30:141-147.

38. Bourke M, Hayes A, Doyle M, McCarroll M. A comparison of regularly administered sustained release oral morphine with intramuscular morphine for control of postoperative pain. Anesth Analg. 2000;90:427-427.

39. De Paepe P, Belpaire F, Buylaer W. Pharmacokinetic and pharmacodynamic considerations when treating patient with sepsis and septic shock. Clin Pharmacokinet. 2002;41:1135-1151.

40. Buck ML, Wigins BS, Sesler JM. Intraosseous drug administration in children and adults during cardiopulmonary resuscitation. Ann Pharmacother. 2007;41:1679-1686.
41. Galinski M, Dolveck F, Borron SW, et al. A randomized, double-blind study comparing morphine with fentanyl in prehospital analgesia. Am J Emerg Med. 2005;23:114119.

42. Thomas SH, Rago O, Harrison T, Biddinger PD, Wedel SK. Fentanyl trauma analgesia use in air medical scene transports. J Emerg Med. 2005;29:179-187.

43. Bisanzo M, Nichols K, Hammerstedt H, et al. Nurseadministered ketamine sedation in an emergency department in rural Uganda. Ann Emerg Med. 2012;59:268-275.

44. Halstead SM, Deakkyne SJ, Bajal L, Enzenauer R, Roosevelt GE. The effect of ketamine on intraocular pressure in pediatric patients during procedural sedation. Acad Emerg Med. 2012;19:1145-1150.

45. Grocott MPW, Johannson L. Ketamine for emergency anaesthesia at very high altitude (4243 m above sea-level). Anaesthesia. 2007;62:959-962.

46. Gros T, Viel E, Ripart J, Delire V, Eledjam JJ, Sebbane M. Bloc fémoral en analgésie préhospitalière pour traumatisme du membre inférieur. Enquête de pratique observationnelle sur 107 cas. Ann Fr Anesth Reanim. 2012;31:846-849.

47. Wu JJ, Lollo L, Grabinsky A. Regional anesthesia in trauma medicine. Anesthesiol Res Pract. 2011;2011:1-7.

48. Simpson PM, McCabe B, Bendall JC, Cone DC, Middleton PM. Paramedic-performed digital nerve block to facilitate field reduction of a dislocated finger. Prehosp Emerg Care. 2012;16:415-417. 